\title{
Spontaneous ovulation and pregnancy in women with polycystic ovarian disease; a cross sectional study
}

\author{
Mostafa A. Sleem, Ibrahim I. Mohamed, Mahmoud S. Zakherah, \\ Ahmed M. Abbas*, Momen A. Kamel
}

Department of Obstetrics and Gynecology, Woman's Health Hospital, Faculty of Medicine, Assiut University, Egypt

Received: 19 November 2017

Accepted: 19 December 2017

\section{*Correspondence:}

Dr. Ahmed M. Abbas,

E-mail: bmr90@hotmail.com

Copyright: (C) the author(s), publisher and licensee Medip Academy. This is an open-access article distributed under the terms of the Creative Commons Attribution Non-Commercial License, which permits unrestricted non-commercial use, distribution, and reproduction in any medium, provided the original work is properly cited.

\begin{abstract}
Background: Polycystic ovary disease (PCOD) is the most common endocrine disorder in women of reproductive age, with a prevalence of approximately $5-10 \%$. This study aims to assess the rate of spontaneous ovulation and pregnancy in patients. The present study was a cross sectional study conducted at Woman's Health Hospital, Assiut University, Assiut, Egypt.

Methods: The current study was a cross sectional study carried out in Assiut Women's Health Hospital between the $1^{\text {st }}$ October 2016 and $31^{\text {st }}$ July 2017. The patients were selected as infertile patients with PCOD. The patient ages range between 20 and 35 years. The BMI is between 18 and $30 \mathrm{Kg} / \mathrm{m}^{2}$. The main outcome measure was the rate of spontaneous ovulation and spontaneous pregnancy in the 3 cycles.

Results: The mean age of the study participants was $26.64 \pm 4.59$ years and the mean BMI was $24.46 \pm 2.62 \mathrm{Kg} / \mathrm{m}^{2}$. The sonographic ovarian volume was $12.47 \pm 0.69 \mathrm{~mm}^{3}$ for the right ovary and $12.74 \pm 0.73 \mathrm{~mm}^{3}$ for the left ovary. No difference in the serum FSH, $\mathrm{LH}, \mathrm{FSH} / \mathrm{LH}$ ratio and prolactin over the 3 consecutive cycles. The rate of spontaneous ovulation in the 3 cycles was 6 women $(8.6 \%)$ and 2 cases $(2.8 \%)$ became pregnant spontaneously during the study period. There is no statistical significant difference between ovulating and non-ovulating women according to the BMI and ovarian volume.

Conclusions: The present study concluded that the rate of spontaneous ovulation was $8.6 \%$ in women with PCOD within 3 cycles with no adverse effects of drugs or surgical interference.
\end{abstract}

Keywords: Infertility, Ovulation, Polycystic ovarian disease, Pregnancy

\section{INTRODUCTION}

Polycystic ovary disease (PCOD) is the most common endocrine disorder in women of reproductive age, with a prevalence of approximately $5-10 \%{ }^{1}$ The principal features of PCOD include androgen excess, ovulatory dysfunction, and/or polycystic ovaries. ${ }^{2}$

PCOD is also associated with insulin resistance (IR), obesity and lipid metabolism disorders, as well as infertility, although these findings have not been addressed in the Rotterdam criteria. $^{3}$ Recent studies suggest that anovulation resulting from ovarian follicle abnormalities in PCOD patients is 2-fold of normal ovaries.

Firstly, early follicular growth is excessive, thus women with PCOD are characterized by an excessive number of small antral follicles. Secondly, the selection of one follicle and its further maturation to a dominant follicle does not occur. This abnormality in the folliculogenesis leads to menstrual dysfunction presented as oligomenorrhea or amenorrhea. ${ }^{4}$ A related mechanism of 
hormonal dysfunction in PCOD is that of malfunction in lutenizing hormone (LH) and follicle- stimulating hormone (FSH) production and regulation. ${ }^{5}$

Treatment of anovulation associated with PCOD involving many lines of treatment starting with weight reduction, metformin, ovulation induction drugs as clomiphene citrate (CC). ${ }^{6}$ The second-line treatment involves gonadotropins or laparoscopic ovarian drilling (LOD). ${ }^{2}$ The main drawbacks of LOD are the possibility of occurrence of premature ovarian failure, decrease ovarian reserve and adhesions. ${ }^{7,8}$

This study aims to assess the rate of spontaneous ovulation and pregnancy in patients with PCOD. Additionally, we tried to find a relation between the hormonal level of anti-mullerian hormone (AMH), LH/FSH ratio, ovarian volume, body mass index (BMI) and spontaneous ovulation.

\section{METHODS}

The current study was a cross sectional study carried out in Assiut Women's Health Hospital between the $1^{\text {st }}$ of October 2016 and the $31^{\text {st }}$ of July 2017. The institutional ethical review board approved the study.

\section{Eligible participants}

All eligible women who presented to the Infertility clinic of the aforementioned hospital were invited to participate in the study. The patients were selected as infertile patients with PCOD.

The patient ages range between 20 and 35 years. The BMI is between 18 and $30 \mathrm{Kg} / \mathrm{m}^{2}$. PCOD women were diagnosed according to the 2003 ESHRE/ASRM (Rotterdam) criteria and their partners had normal semen analysis (according to WHO criteria).

The Rotterdam criteria for diagnosis of PCO include presence of at least 2 out of 3 of the following criteria:

- Oligomenorrhea or amenorrhea,

- Clinical and biochemical signs of hyperandrogenism

- Ultrasonographic picture of PCO $(<12$ subcortical follicles (2-9 $\mathrm{mm}$ in diameter) with dense stroma and/or increased ovarian volume (more than $\left.10 \mathrm{~cm}^{3}\right) .{ }^{9}$

We excluded infertile patients due to causes other than PCO (tubal block, abnormal semen analysis), patients with endometriosis, fibroid uterus, those with previous pelvic surgery, those with chronic medical diseases as diabetes mellitus, liver diseases.

Additionally, women with hyperprolactinemia or other endocrine disorders that may affect fertility were excluded from the study. Women suffering from other causes of hyperandrogenism as congenital adrenal hyperplasia, androgen secreting tumors and Cushing's syndrome were also excluded.

A full detailed history including menstrual history, medical history, surgical history, past history, obstetric history was taken from all participants. General, abdominal and pelvic examination was done with complete investigations. All women gave their written informed consent.

Ultrasonography was performed using transvaginal sonography probe $7.5 \mathrm{mHz}$ (Medison X6, South Korea) to confirm the diagnosis of PCO, to assess the ovarian volume and to assess the ovulation in follow-up visits. The ovarian volume was measured using the following formula (length $\times$ width $\times$ thickness $\times 0.523$ ). The procedure was done on the two ovaries and the summation of volumes of both ovaries was calculated giving the total ovarian volume (TOV).

Blood samples were collected at day 3 to measure the plasma concentrations of $\mathrm{FSH}, \mathrm{LH}, \mathrm{AMH}$, testosterone and fasting blood glucose. $5 \mathrm{cc}$ blood sample was taken from each patient and maintained in tubes containing cloth activator material (serum separation, Stago, France).

The samples were centrifuged with $3000 \mathrm{rpm}$ and the serum was collected at $2 \mathrm{ml}$ micro tubes and stored at $20^{\circ} \mathrm{C}$ freezer until subsequent analysis. Plasma samples were assayed for the hormones in duplicate using a commercial enzyme-linked immunosorbant assay kit (Pritest ECO, ELISA, ROBOnik (India) Pvt, Ltd) according to the manufacturer's protocol.

All patients were followed up for 3 cycles by hormonal assay and ultrasonographic assessment of the ovulation occurrence. The main outcome measure was the rate of spontaneous ovulation and spontaneous pregnancy in the 3 cycles.

\section{Statistical analysis}

The data was collected and entered into a Microsoft Access database and was analyzed using the Statistical Package for Social Science (SPSS Inc., Chicago, version 21). The demographic characteristics and baseline data werecompared between the groups. The outcome variables were calculated using an independent-t-test between groups. For dichotomous variables, chi-square was used to estimate the significance value. For analysis, $\mathrm{p}<0.05$ was considered to be significant.

\section{RESULTS}

Eighty-four women were approached to participate in the study. Eleven women have been excluded. Moreover, three women declined participation in the study. The demographic data of the study participants are shown in Table 1. The mean age of the study participants was 
$26.64 \pm 4.59$ years and the mean BMI was $24.46 \pm 2.62 \mathrm{Kg} / \mathrm{m}^{2}$.

Table 1: The demographic criteria of the study participants.

\begin{tabular}{|c|c|c|}
\hline Parameters & No. $(n=70)$ & $\%$ \\
\hline \multicolumn{3}{|l|}{ Age (years) } \\
\hline$<25$ years & 23 & 32.9 \\
\hline $25-<30$ years & 24 & 34.3 \\
\hline$\geq 30$ & 23 & 32.9 \\
\hline Mean \pm SD (range) & \multicolumn{2}{|c|}{$26.64 \pm 4.59(20.0-38.0)$} \\
\hline \multicolumn{3}{|l|}{ Parity } \\
\hline Nullipara & 48 & 68.6 \\
\hline One & 21 & 30.0 \\
\hline Two & 1 & 1.4 \\
\hline \multicolumn{3}{|c|}{ Methods of conception $(n=22)$} \\
\hline Spontaneous & 5 & 22.7 \\
\hline Induced & 17 & 77.3 \\
\hline \multicolumn{3}{|c|}{ Duration of infertility (years) } \\
\hline $1-2$ years & 40 & 57.1 \\
\hline$>2$ years & 30 & 42.9 \\
\hline Mean \pm SD (range) & \multicolumn{2}{|c|}{$2.13 \pm 1.49(1.0-6.0)$} \\
\hline \multicolumn{3}{|l|}{ BMI } \\
\hline Normal & 41 & 58.6 \\
\hline Overweight & 29 & 41.4 \\
\hline Mean \pm SD (range) & \multicolumn{2}{|c|}{$24.46 \pm 2.62(20.0-28.0)$} \\
\hline
\end{tabular}

SD; standard deviation, BMI; body mass index

The sonographic ovarian volume was $12.47 \pm 0.69 \mathrm{~mm}^{3}$ for the right ovary and $12.74 \pm 0.73 \mathrm{~mm}^{3}$ for the left ovary. No difference in the serum FSH, $\mathrm{LH}, \mathrm{FSH} / \mathrm{LH}$ ratio and prolactin over the 3 consecutive cycles (Figure 1).

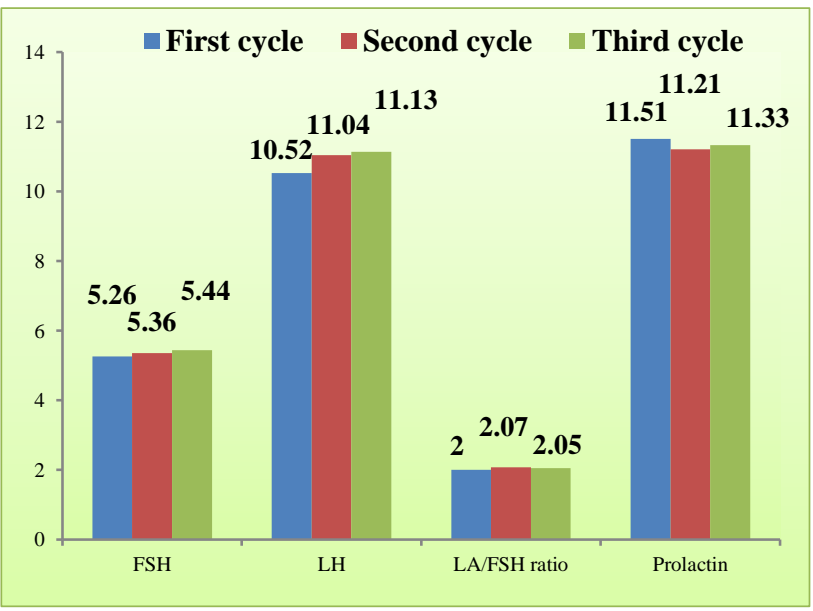

Figure 1: Hormonal profile of the study participants in the 3 consecutive cycles.

The rate of spontaneous ovulation in the 3 cycles was 6 women $(8.6 \%)$ and 2 cases $(2.8 \%)$ became pregnant spontaneously during the study period. Figure 2 shows the baseline investigations in the first cycle between ovulating and non-ovulating women.

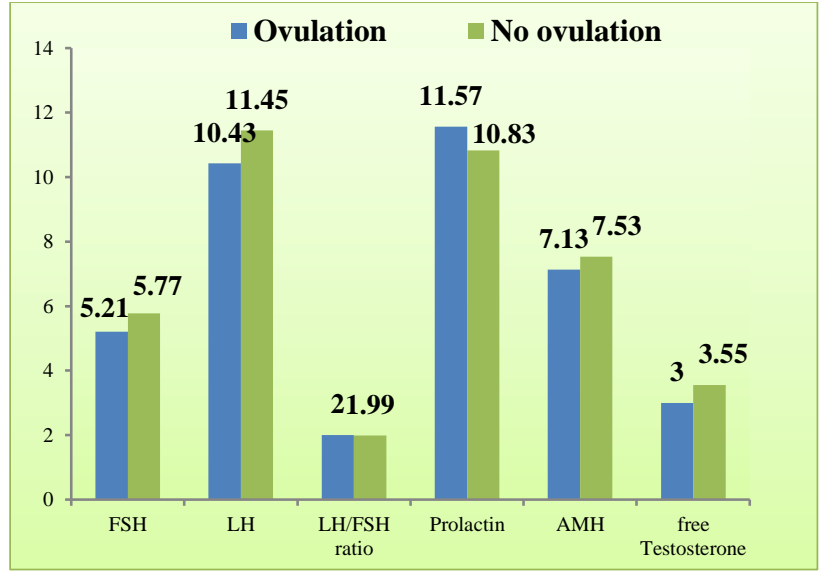

Figure 2: Hormonal profile in the first cycle at baseline according to ovulation among study participants.

Table 2 shows there is no significant difference in the results of hormonal analysis between ovulating and nonovulating women in the second cycle. However, in the third cycle, the mean FSH and LH was significantly higher in the ovulating group $(\mathrm{p}=0.040,0.043$ respectively).

Table 2: The hormonal results at the second and third cycle among the study participants.

\begin{tabular}{|c|c|c|c|c|}
\hline & & $\begin{array}{l}\text { No } \\
\text { ovulation } \\
(n=64)\end{array}$ & $\begin{array}{l}\text { Ovulation } \\
(n=6)\end{array}$ & $\begin{array}{l}\text { P- } \\
\text { value }\end{array}$ \\
\hline \multirow{12}{*}{$\begin{array}{l}\text { Second } \\
\text { cycle }\end{array}$} & FSH & & & \multirow{3}{*}{0.173} \\
\hline & Mean \pm SD & $5.33 \pm 0.68$ & $5.68 \pm 0.58$ & \\
\hline & Range & $3.9-6.5$ & $5.0-6.3$ & \\
\hline & LH & & & \multirow{3}{*}{0.138} \\
\hline & Mean \pm SD & $10.97 \pm 1.23$ & $11.72 \pm 1.02$ & \\
\hline & Range & $8.0-13.5$ & $10.2-13.0$ & \\
\hline & \multicolumn{3}{|c|}{ LH/FSH ratio } & \multirow{3}{*}{0.635} \\
\hline & Mean \pm SD & $2.07 \pm 0.17$ & $2.07 \pm 0.10$ & \\
\hline & Range & $1.5-2.6$ & $1.9-2.2$ & \\
\hline & \multicolumn{3}{|l|}{ Prolactin } & \multirow{3}{*}{0.108} \\
\hline & Mean \pm SD & $11.31 \pm 1.53$ & $10.17 \pm 1.72$ & \\
\hline & Range & $8.0-15.0$ & $8.0-13.0$ & \\
\hline \multirow{12}{*}{$\begin{array}{l}\text { Third } \\
\text { cycle }\end{array}$} & FSH & & & \multirow{3}{*}{$0.040 *$} \\
\hline & Mean \pm SD & $5.40 \pm 0.59$ & $5.90 \pm 0.34$ & \\
\hline & Range & $4.2-6.5$ & $5.3-6.3$ & \\
\hline & \multicolumn{3}{|l|}{ LH } & \multirow{3}{*}{$0.043 *$} \\
\hline & Mean \pm SD & $11.04 \pm 1.23$ & $12.12 \pm 0.67$ & \\
\hline & Range & $8.5-13.0$ & $11.0-13.0$ & \\
\hline & \multicolumn{3}{|c|}{ LH/FSH ratio } & \multirow{3}{*}{0.636} \\
\hline & Mean \pm SD & $2.05 \pm 0.13$ & $2.05 \pm 0.02$ & \\
\hline & Range & $1.6-2.4$ & $2.0-2.1$ & \\
\hline & \multicolumn{3}{|l|}{ Prolactin } & \multirow{3}{*}{0.059} \\
\hline & Mean \pm SD & $11.45 \pm 1.97$ & $10.00 \pm 1.67$ & \\
\hline & Range & $7.0-16.0$ & $7.0-12.0$ & \\
\hline
\end{tabular}

SD: standard ratio; FSH: Follicle stimulating hormone; LH: Luteinizing hormone; *Statistical significant difference 
Table 3: The relation between the ovarian volume and BMI and spontaneous ovulation.

\begin{tabular}{|llll|}
\hline & $\begin{array}{l}\text { No ovulation } \\
(\mathrm{n}=64)\end{array}$ & $\begin{array}{l}\text { Ovulation } \\
(\mathrm{n}=6)\end{array}$ & P-value \\
Mean \pm SD & Mean \pm SD & \\
\hline Ovarian volume & & \\
\hline Right & $12.32 \pm 0.57$ & $12.61 \pm 0.73$ & 0.257 \\
\hline Left & $12.66 \pm 0.68$ & $12.80 \pm 0.79$ & 0.641 \\
\hline BMI $\left(\mathrm{kg} / \mathrm{m}^{2}\right)$ & $25.33 \pm 2.42$ & $24.38 \pm 2.64$ & 0.395 \\
\hline \multicolumn{2}{|l|}{ SD: Standard deviation; BMI: Body mass index } \\
\hline
\end{tabular}

Table 3 shows that there is no statistical significant difference between ovulating and non-ovulating women according to the BMI and ovarian volume.

\section{DISCUSSION}

To the best of our knowledge, no studies had been carried out before to evaluate the rate of spontaneous ovulation in patients with PCOD. The study results conclude that spontaneous ovulation could occur in $8.6 \%$ of patient with PCOD in consecutive 3 cycles without use of any line of treatment. This spontaneous ovulation is related neither to the sonographic ovarian volume nor to the patient BMI.

Obesity is strongly related to PCOD and may be present in up to $50 \%$ of cases. ${ }^{10,11}$ Obese women with PCOD are more likely to suffer from anovulation. This effect on ovulation may be secondary to IR, which in turn results in hyperinsulinemia and stimulation of excess androgen production from the ovaries.

Therefore, weight loss diet has been proven effective in restoring ovulation and achieving pregnancy in many patients with PCOD. ${ }^{12,} 13$ In obese, anovulatory women with PCOD, weight loss of often restores ovulatory cycles. ${ }^{14}$

Clomiphene citrate has been used as a first-line ovulation induction agent for over 40 years. ${ }^{15}$ PCOD patients are sensitive to ovulation induction drugs because of a large number of antral follicles. Although $60 \%-85 \%$ of patients will ovulate on $\mathrm{CC}$, only about one half will get pregnancy. ${ }^{16}$ Absence of pregnancy despite evidence of ovulation may be due to the anti-estrogenic effects of CC on the endometrium, which may manifest as a thin endometrium on ultrasound. ${ }^{17}$ Metformin combined with $\mathrm{CC}$ may increase ovulation rates and pregnancy rates but does not significantly improve the live birth rate over that of CC alone. ${ }^{18}$

The use of aromatase inhibitors in ovulation induction increased the ovulation and pregnancy rates and these agents appear to have less anti-estrogen effect on the endometrium. ${ }^{19}$ LOD is one of the lines of treatments for anovulation due to PCOD. It induces ovulation by decreasing the ovarian theca and thus reducing androgen production. ${ }^{20}$
In our study the rate of spontaneous ovulation was $8.6 \%$ in 3 cycles only. The women included in the study were of different ages and BMI, however, no difference between ovulating and non-ovulating women as regard the BMI. Hormonal profile of the ovulating women showed significantly higher serum FSH, LH at the $3^{\text {rd }}$ cycle than the non-ovulating women.

The main limitation of the present study was the small number of patients included and the short duration of evaluation of the rate of spontaneous ovulation and pregnancy.

\section{CONCLUSION}

Our study concluded that the rate of spontaneous ovulation was $8.6 \%$ in women with PCOD within 3 cycles with no adverse effects of drugs or surgical interference. We recommend follow-up of cases newly diagnosed as PCOD without ovulation induction drugs for 3-6 months as spontaneous ovulation and pregnancy could be achieved in higher rates without hazards of medical or surgical treatment of PCOD.

\section{Funding: No funding sources}

Conflict of interest: None declared

Ethical approval: The study was approved by the Institutional Ethics Committee

\section{REFERENCES}

1. Ehrman DA. Polycystic ovary syndrome. New Eng J Med. 2005;352:1223-36.

2. Thomas S, Sudharshini S. Polycystic ovarian syndrome: treatment options for infertility. Current Medical Issues. 2016;14(4):87-93.

3. Pandey S, Bhattacharya S. Impact of obesity on gynecology. Womens Health (Lond). 2010;6(1):10717.

4. Jonard S, Dewailly D. The follicular excess in polycystic ovaries, due to intraovarian hyperandrogenism, may be the main culprit for the follicular arrest. Hum Reprod Update. 2004;10(2):107-17.

5. Solorzano BCM, McCartney CR, Blank SK, Knudsen KL, Marshall JC. Hyperandrogenaemia in adolescent girls: origins of abnormal gonadotropinreleasing hormone secretion. BJOG. 2002;117(2):143-9.

6. Diamanti-Kandarakis E, Kouli CR, Bergiele AT, Filandra FA, Tsianateli TC, Spina GG, et al. A survey of the polycystic ovary syndrome in the Greek island of Lesbos: hormonal and metabolic profile. J Clin Endocrinol Metab. 1999;84:4006-11.

7. Al-Hussaini TK, Zakhera MS, Abdel-Aleem M, Abbas AM. Premature ovarian failure/dysfunction following surgical treatment of polycystic ovarian syndrome: a case series. Middle East Fertil Soc. 2017;22:233-5. 
8. Salem MN, Ahmed SR, Abbas AM, Salem AN, Sabala AM. Short term effects of laparoscopic ovarian drilling in clomiphene citrate resistant patients with polycystic ovary syndrome. Middle East Fertil Soc. 2017;22:290-4.

9. Rotterdam ESHRE/ASRM-Sponsored PCOS Consensus Workshop Group. Revised 2003 consensus on diagnostic criteria and long-term health risks related to polycystic ovary syndrome. Fertil Steril. 2004;81(1):19-25.

10. Hoeger KM. Obesity and lifestyle management in polycystic ovary syndrome. Clin Obstet Gynecol. 2007;50:277-94.

11. Pasquali R, Gambineri A, Pagotto U. The impact of obesity on reproduction in women with polycystic ovary syndrome. BJOG. 2006;113:1148-59.

12. Clark AM, Thornley B, Tomlinson L, Galletley C, Norman RJ. Weight loss in obese infertile women results in improvement in reproductive outcome for all forms of fertility treatment. Hum Reprod. 1998;13:1502-5.

13. Tolino A, Gambardella V, Caccavale C, D'Ettore A, Giannotti F, D'Anto V, et al. Evaluation of ovarian functionality after a dietary treatment in obese women with polycystic ovary syndrome. Eur J Obstet Gynecol Reprod Biol. 2005;119:87-93.

14. Speroff L, Fritz MA. Clinical gynecologic endocrinology and infertility. $7^{\text {th }}$ ed. Pennsylvania: Lippincott Williams and Wilkins; 2005.

15. Kafy $S$, Tulandi $T$. New advances in ovulation induction. Curr Opin Obstet Gynecol. 2007;19:24852.
16. Neveu N, Granger L, St. Michel P, Lavoie HB. Comparison of clomiphene citrate, metformin, or the combination of both for first-line ovulation induction and achievement of pregnancy in 154 women with polycystic ovary syndrome. Fertil Steril. 2007;87:113-20.

17. Randall JM, Templeton A. Transvaginal sonographic assessment of follicular and endometrial growth in spontaneous and clomiphene citrate cycles. Fertil Steril. 1991;56:208-12.

18. Creanga AA, Bradley HM, McCormick C, Takacs Witkop C. Use of metformin in polycystic ovary syndrome: a metaanalysis. Obstet Gynecol. 2008;111:959-68.

19. Bayar U, Basaran M, Kiran S, Coskun A, Gezer S. Use of an aromatase inhibitor in patients with polycystic ovary syndrome: a prospective randomized trial. Fertil Steril. 2006;86:1447-51

20. Mercorio F, Mercorio A, Di Spiezio Sardo A, Barba GV, Pellicano M, Mappi C. Evaluation of ovarian adhesion formation after laparoscopic ovarian drilling by second-look minilaparoscopy. Fertil Steril. 2008;89:1229-33.

Cite this article as: Sleem MA, Mohamed II, Zakherah MS, Abbas AA, Kamel MA. Spontaneous ovulation and pregnancy in women with polycystic ovarian disease; a cross sectional study. Int J Reprod Contracept Obstet Gynecol 2018;7:359-63. 